\title{
Hemşirelik ve Ebelik Öğrencilerinde Malpraktis
}

\author{
Malpractice in Nursing and Midwifery Students
}

\author{
Talip MANKAN ${ }^{\mathrm{a}}$, Gülcan BAHÇECIOĞLU TURAN ${ }^{\mathrm{b}}$, Hilal POLAT ${ }^{\mathrm{c}}$
}

\begin{abstract}
ÖZET Amaç: Bu araştırma hemşirelik ve ebelik öğrencilerinin tıbbi hata yapma eğilimlerini incelemek amacıyla yapılmıştır. Yöntem: Araştırmanın örneklemini, Kasım 2015-Haziran 2016 tarihleri arasında Fırat Üniversitesi Sağlık Bilimleri Fakültesi’nde okuyan intörn hemşirelik ve ebelik öğrencileri oluşturmuştur (202). Veri toplamada Kişisel Bilgi Formu ve Malpraktis Eğilim Ölçeği ( MEÖ) kullanılmıştır. Bulgular: Araştırmaya katılan intörn öğrencilerinin \%62.4'ünün (126) hemşirelik bölümü öğrencileri oluşturduğu, \%31.7'sinin kadın doğum kliniğinde staj yaptığı, \%36.1'inin günlük 1-5 hastaya bakım verdiği belirlenmiştir. Eğitiminiz süresince hasta güvenliğini tehlikeye sokacak en az bir hata yaptınız mı? Sorusuna; araştırma kapsamındaki intörn hemşirelik ve ebelik öğrencilerinin \%89.6'sı (181) hayır cevabını; Eğitiminiz süresince ekip arkadaşlarınızın hasta güvenliğini tehlikeye sokacak herhangi bir hatasını gördünüz mü? Sorusuna ise intörn hemşirelik ve ebelik öğrencilerinin, \%74.3’ü (150) hayır cevabını vermiştir. Araştırma kapsamında intörn hemşirelik ve ebelik öğrencilerine staj yaptıkları hastanede en çok karşılaşılan tıbbi hataların hangileri olduğuna ilişkin sorular yöneltilmiş ve en sık karşılaşılan hataların sırasıyla; hastane enfeksiyonları, tedavide gecikme veya yapmama, ameliyat sonrası komplikasyonları ve iğne/kesici alet yaralanmaları olduğu saptanmıştır. İntörn hemşirelik ve ebelik öğrencileri tıbbi hataya yol açan ilk 5 neden olarak stres, yorgunluk, iş yükünün fazla olması, mesleki bilginin yetersiz olması ve tecrübesizlik olduğunu belirtmişlerdir. Sonuç: Malpraktis Eğilim Ölçeğinin toplam puan ortalaması 200. $62 \pm 33.07$ (54-245 puan arası) olup düşük düzeyde tıbbi hata eğilimi saptanmıştır.
\end{abstract}

Anahtar Kelimeler: Ebe, hemşire, intörn öğrenci, tıbbi hata, malpraktis

ABSTRACT Objective: This study was conducted to investigate the malpractice tendencies of nursing and midwifery students. Method : The study sample consisted of nursing intern nursing and midwifery students ( $n=202)$ studying at the Firat University, Faculty of Health Sciences between November 2015 and June 2016. Personal Information Form and the Educational Malpractice Scale (EMS) was used for data collection. Results: Of the intern students included in the study, 62.4\% (126) was found to be nursing students, $31.7 \%$ was doing internship in the maternity clinic, and 36.1\% was found to provide care for 1 to 5 patients daily. The "During your education, have you ever made at least one mistake that might jeopardize the safety of the patients?" question was responded with 'No' by $89.6 \%$ (181) of the nursing and midwifery students included in the study. And, the "During your education, have you ever seen any mistake of your team that might jeopardize the safety of the patients?" question was answered with 'No' by $74.3 \%$ (150) of the nursing and midwifery students. The nursing and midwifery students included in the study were asked about the most common malpractices faced in their hospital of internship, and the most common medical errors were found to be hospital infections, postponed or unperformed treatment, post-operative complications, and needle/sharp object injuries. The first five causes of malpractice reported by the nursing and midwifery students were stress, excessive workload, inadequate professional knowledge, and inexperience. Conclusion:The mean Educational Malpractice Scale score was found to be 200.62 \pm 33.07 (in the range of 54-245 points), indicating a lower level of malpractice tendency.

Keywords: İntern student, malpractice, medical error, midwife, nurse.

\section{Giriş}

Tıbbi hatalı uygulama sağlık hizmeti sunan bir profesyonelin uygun ve etik olmayan bir davranışta bulunması, mesleki uygulamalarda yetersiz ve ihmalkâr davranması sonucu hastanın yaralanmas1, zarar görmesi, ya da ölümüne neden olunması şeklinde tanımlanmaktadır. ${ }^{1-3}$ Latince "mala-praxis" kelimesinden türemiş olup günümüzde malpraktis, olarak adlandirılmaktadır. ${ }^{4}$
Tibbi hatalar aktif ve gizli hatalar olarak sınıflandırılmıştır. Etkileri anında hissedilen hatalar aktif hatalar olarak tanımlanmıştır. Gizli hatalar ise, yönetim yetersizliği, hatalı bakım, kötü idari kararlar ve zayıf yapılanmış kuruluşları içeren ve sağlık personeli kontrolü dişında gerçekleşen ve hatalar olarak belirtilmiştir. ${ }^{5}$ Tıbbi uygulama hataları temel olarak

Geliş Tarihi/Received: 12-12-2016 Kabul Tarihi/Accepted: 28-03-2017

a Hemşire, İnönü Üniversitesi Sağlık Bilimleri Fakültesi Hemşirelik Esasları Doktora Öğrencisi, Malatya talipmankan@hotmail.com

b Arş. Gör. Atatürk Üniversitesi Sağlık Bilimleri Fakültesi İç Hastalıkları Hemşireliği AD. Erzurum,glcnbah@hotmail.com,

c Öğr. Gör. Fırat Üniversitesi Sağlık Bilimleri Fakültesi Hemşirelik Bölümü, Elazığ hilaltpolat@hotmail.com

Sorumlu yazar /Correspondence: Gülcan BAHÇECİOĞLU TURAN, Atatürk Üniversitesi Sağlık Bilimleri Fakültesi İç Hastalıkları Hemşireliği AD. Erzurum, glcnbah@hotmail.com, 
tıbbi işleme, ihmale ve uygulamaya bağlı olarak tanı, tedavi, koruyucu tedavi ve diğer hatalar olmak üzere dört kısma ayrılır. ${ }^{6}$

En sık karşılaşılan tıbbi hatalar; ilaç hataları, hastane enfeksiyonları, bulguların atlanması, tetkiklerin eksik incelenmesi sonucu teşhiste oluşan hatalar; girişimsel, yanlış taraf cerrahisi, hastanın düşmesi, kazalar, hastanın yeterli beslenememesi, cihaz desteğinin hatalı kesilmesi ve hastanın taburcu olması sirasinda yeterli bilgilendirilmemesi ve taburcu olduktan sonra bakımına destek olunmamasına bağlı oluşan hatalar şeklinde belirtilmiştir. ${ }^{7}$ Tibbi hatalar tedavinin uzamasina, yeni sakatlikların veya komplikasyonlarm tedavisi sonucunda ilave maliyetlere, manevi hasara, sağlik profesyonellerinin moral ve motivasyon kaybına, sağlık personeline güvensizliğine ve toplumda sağl1k sisteminden memnuniyetsizliğine neden olmaktadır. ${ }^{8,9}$ Amerika'da yapılan bir çalışmada ilaç hatalarına bağlı ölümlerin yılda 98.000'e kadar ulaşabileceği ileri sürülmektedir. Ülkemizde ise tıbbi hataların boyutları tam olarak bilinmemektedir. ${ }^{10,11} 2000$ 2007 yıllar1 arasında basina yansiyan haberler ele alınarak yapılan retrospektif bir çalışmaya göre, tıbbi hataları yapan kişilerin \%65.2'sinin hekimler, \%12.2'sinin ise hemşireler oluşturduğu belirlenmiştir. En çok tıbbi hatanın ise \%43.6'l1k bir oranla ameliyathane bölümünde yapılmış olduğu saptanmıştır. ${ }^{12}$

Tıbbi hatalar tüm sağlık çalışanları için önemli bir konudur. Hemşireler ve ebeler tıbbi uygulamalarda doğrudan görev aldığı ve yaptıkları yanlış uygulamalar hastada yaşamsal tehlike oluşturabileceği için tıbbi hatalı uygulamalar hemşire ve ebeler açısından daha fazla önem taşımaktadır. Bu çalışmada amaç, hemşire ve ebelik öğrencilerinin tıbbi hatalara eğilim düzeylerinin belirlenmesidir. Tibbi hataların önlenmesi amacıyla alınacak tedbirlerde, tıbbi hatalara eğilim düzeylerinin bilinmesinin önemli olduğu düşünülmektedir.

\section{Gereç ve Yöntem}

Araştırmanın Türü: Tanımlayıcı olarak yapılmıştır.

Araştırmanın Yapıldığı Yer ve Zaman: Araştırma Kasım 2015- Haziran 2016 tarihleri arasında, Fırat Üniversitesi Sağlık Bilimleri Fakültesi'nde yürütülmüştür.

Evren ve Örneklem: Araştırmanın evrenini Sağlık Bilimleri Fakültesi'nde öğrenim gören 4. sınıf hemşirelik ve ebelik öğrencisi oluşturmuştur. Araştırmada örneklem seçimine gidilmemiş, araştırmaya katılmayı kabul eden öğrenciler araştırma kapsamına alınmış ve araştırma 202 öğrenci ile tamamlanmıştır.

Veri Toplama Formları: Verilerin toplanmasında; anket formu ve Hemşirelikte Tibbi Hataya Eğilim Ölçeği kullanılmıştır.

Anket Formu: Araştırmacılar tarafindan geliştirilen bu form üç bölümden oluşmaktadır. Birinci bölümde; öğrencilerin sosyo-demografik (yaş, cinsiyet, klinik eğitim düzeyi vb.) özellikleri, günlük bakım verilen hasta sayısı ve tıbbi hata yapma durumu ile ilgili 9 soru bulunmaktadır. İkinci bölümde; kliniklerde yapılan tıbbi hatalara ilişkin 32 soru bulunmaktadır. Üçüncü bölümde ise; tıbbi hataları nedenlerini belirlemeye ilișkin 23 soru bulunmaktadır.

Hemşirelikte Tıbbi Hataya Eğilim Ölçeği: Hemşirelikte Tıbbi Hataya Eğilim Ölçeği 2010 y1lında Özata ve Altunkan tarafindan hemşirelerin tıbbi hata eğilimlerini ölçmek amacıyla geliştirilmiştir. ${ }^{13}$ Ölçek 49 maddeden ve ilaç ve transfüzyon uygulamaları (18 madde), düşmeler (5 madde), hastane enfeksiyonları (12 madde), hasta izlemi/malzeme güvenliği (9 madde) ve iletişim (5 madde) olmak üzere 5 alt boyuttan oluşmaktadır. Ölçek 5'li likert tipi olup, ifadeler 1: hiç, 2: çok nadir, 3: zaman zaman, 4: genellikle, 5: her zaman şeklinde değerlendirilmektedir. Ölçeğin değerlendirilmesinde puan ortalamas1 kullanılmaktadır. Ölçeğin ortalama puanı yükseldikçe hemşirelerin tıbbi hata yapma eğilimlerinin düşük olduğu, ortalama puanı düştükçe hemşirelerin tıbbi hata yapma eğilimlerinin yüksek olduğunu göstermektedir. Ölçekten alınabilecek en yüksek puan 245 , en düşük puan ise 49'dur. Ölçeğin Cronbach alfa katsayısı 0.95 olduğu belirtilmiştir. ${ }^{13} \mathrm{Bu}$ çalışmada ölçeğin Cronbach alfa katsayısı 0.97 olarak bulunmuştur.

\section{Verilerin Toplanması}

Araştırmanın verileri Ocak - Şubat 2016 tarihleri arasında toplanmıştır. Araştırmaya katılan öğrencilere araştırma hakkında bilgi verildikten sonra anket formu kendilerine dağıtılmış ve doldurmaları istenmiştir. Anket formunu cevaplama süresi yaklaşı 20-25 dakika kadardır. 


\section{Verilerin Değerlendirilmesi}

Araştırmanın verilerinin istatistiksel analizi SPSS (Statistical Package for Social Science) 21 paket programı kullanılarak değerlendirilmiştir. Verilerin özetlenmesinde; kategorik değişkenler için sayı ve yüzde, sayısal değişkenler için ortalama, standart sapma, minimum ve maksimum değerler ve ölçek puan ortalamalarının karşılaştırılmasında bağımsız gruplarda t testi ve Kruskal-Wallis testi kullanılmıştır.

\section{Araştırmanın Etik İlkeleri}

Araştırmanın planlanması aşamasında öncelikle Fırat Üniversitesi Girişimsel Olmayan Araştırmalar Etik Kurulu onayı ve Firat Üniversitesi Sağlık Bilimleri Fakültesi Dekanlığından gerekli izinler alınmıştır. Araştırmaya alınacak öğrencilerin gönüllü ve istekli olmalarına özen gösterilmiş, çalışmaya katılıp katılmamakta özgür oldukları bildirilmiştir.

\section{Bulgular}

Araştırmaya katılan intörn öğrencilerinin tanıtıcı özellikleri Tablo 1'de verilmiştir. Araştırmaya katılan intörn öğrencilerin \%77.2'sinin kadın olduğu, \%62.4'ünün hemşirelik bölümü öğrencisi olduğu, \%31.8'inin özel birimlerde (ameliyathane, yoğun bakım, acil, poliklinik) uygulama yaptığı, \%36.1'inin günde 1-5 hastaya bakım verdiği tespit edilmiştir. Öğrencilerin \%89.6'sının eğitim süresince tıbbi hata yapmadığını, \%25.7'isinin ise eğitim süresince arkadaşlarının tıbbi hata yaptıklarını gördüklerini belirtmişlerdir (Tablo 1). Öğrencilerin yaş ortalamasının 22.18 \pm 1.63 (Min:21Mak:31) olduğu tespit edilmiştir

Araştırma katılan intörn öğrencilere uygulama yaptıkları hastanelerde en çok karşılaşılan tıbbi hataların hangileri olduğuna ilişskin sorular yöneltilmiş ve en s1k karşılaşılan hataların; hastane enfeksiyonları (\%87.6), tedavide gecikme veya yapmama (\%78.2), ameliyat sonras1 komplikasyonlar (\%77.7), iğne/kesici alet yaralanmaları (\%77.2), ve ameliyat komplikasyonları (\%74.3) olduğu tespit edilmiştir. En az karşılaşılan hataların ise sıra beklemeye bağlı ölümler (\%16.3), elektrik şokuna bağlı ölüm (\%17.3) ve son kullanma tarihi geçmiş ilaç kullanımı (\%22.8) olduğu tespit edilmiştir (Tablo 2).

Araştırmaya katılan intörn öğrencilere tıbbi hataların nedenlerine ilişkin sorular yöneltilmiş ve tıbbi hatalara yol açan nedenlerin; stres (\%98.5), yorgunluk (\%98.0), iş yükünün fazla olmas1 (\%96.5) ve mesleki bilginin yetersiz olması (\%96.0) olarak tespit edilmiştir (Tablo 3).

Tablo 1. İntörn Öğrencilerinin Tanıtıcı

Özellikleri (N=202)

\begin{tabular}{lcc}
\hline Tanıtıcı & $\mathrm{n}$ & $\%$ \\
Özellikler & & \\
\hline Cinsiyet & & \\
Erkek & 46 & 22.8 \\
Kadın & 156 & 77.2 \\
\hline Bölüm & & \\
Hemşirelik & 126 & 62.4 \\
Ebelik & 76 & 37.6 \\
\hline Klinik & & \\
Dâhili Klinik & 25 & 12.4 \\
Cerrahi Klinik & 23 & 11.4 \\
Kadın Doğum & 64 & 31.7 \\
Kliniği & 27 & 13.4 \\
ASM & 49 & 24.3 \\
Özel Birim & 14 & 6.8 \\
Psikiyatri Kliniği & & \\
\hline Günlük Bakım & & \\
Verilen Hasta & & \\
Sayıs1 & & \\
1-5 & 73 & 36.1 \\
6-10 & 37 & 18.3 \\
11-15 & 22 & 10.9 \\
16-20 & 25 & 12.4 \\
21 hasta ve üstü & 45 & 22.3 \\
\hline Kendinin Hata & & \\
Yapma Durumu & & \\
Evet & 21 & 10.4 \\
Hayır & 181 & 89.6 \\
\hline Arkadaşının Hata & & \\
Yapma Durumu & & \\
Evet & 52 & 25.7 \\
Hayır & 150 & 74.3 \\
\hline
\end{tabular}

Toplam MEÖ puan ortalamasının 200. 62 olduğu, alt ölçeklerin ise; "ilaç ve transfüzyon uygulamaları" 78.36 puan, "düşmeler" 17.98 puan, "iletişim" 19.31 puan, "hasta izlemi ve malzeme güvenliği" 35.23 puan ve "hastane enfeksiyonları" alt ölçeğinin 49.72 puan olduğu tespit edilmiştir (Tablo 4).

\section{Tartışma}

$\mathrm{Bu}$ çalışma, intörn öğrencilerinin staja çıtıkları hastanelerde malpraktis türlerini malpraktis yapılma nedenlerini ve malpraktis eğilim düzeylerini incelemek amacıyla yapılmıştır. 
Tablo 2. Tıbbi Hata Türlerine İlişkin Bulgular $(\mathrm{N}=202)$

\begin{tabular}{lrc}
\hline T1bbi Hata Türleri & \multicolumn{1}{c}{$\mathrm{n}$} & $\%$ \\
\hline 1-Yanlış Taraf Cerrahisi & 69 & 34.1 \\
2- İntihar & 68 & 33.7 \\
3- Sıra Beklemeye Bağlı Ölümler & 33 & 16.3 \\
4- Transfüzyon Hataları & 80 & 39.6 \\
5- Ameliyat Komplikasyonları & 150 & 74.3 \\
6-Ameliyat Sonrası & 157 & 77.7 \\
Komplikasyonlar & & \\
7- Ölümcül veya zarar verici & 106 & 52.5 \\
düşmeler & & \\
8- İnfüzyon Pompaları hataları & 78 & 59.2 \\
9- Hatalı Gaz/Gaz Karışımı & 45 & 48.4 \\
Verilmesi & & \\
10- İğe/Kesici Alet Yaralanmaları & 156 & 77.2 \\
11- Tehlikeli Kısaltmalar & 92 & 45.5 \\
12- Vantilatörle Illişkili Problemler & 78 & 38.6 \\
13- Tedavide gecikme veya & 158 & 78.2 \\
yapmama & & \\
14- Karyolaya Bağlı Yaralanma ve & 81 & 40.1 \\
Ölümler & & \\
15- Hastane Enfeksiyonları & 177 & 87.6 \\
16- Cerrahi Yanıklar & 76 & 37.6 \\
17- Kemoterapi Hataları & 58 & 28.7 \\
18- Ameliyatlarda Yabancı Cisim & 83 & 41.1 \\
Unutulması & & \\
19- Kontamine İlaç veya Kan & 132 & 65.3 \\
Alınması & & \\
20- Araç gerecin bozulmasına bağlı & 139 & 68.8 \\
hatalar & & \\
21- Hastanın Kaçması & 124 & 61.4 \\
22- Tanı Testlerinin Yetersizliği & 116 & 57.2 \\
23- Tanı Hataları & 109 & 54.0 \\
24- Son Kullanma Tarihi Geçmiş & 46 & 22.8 \\
Illaç Kullanımı & & \\
25- Hipoglisemiye Bağlı Ölümler & 51 & 25.2 \\
26- Yatak Yaraları & 117 & 57.9 \\
27- Elektrik Şokuna Bağlı Ölüm & 35 & 17.3 \\
28- Yanlıs doz ilaç uygulaması & 121 & 59.9 \\
29- Yanlı̧ ilaç uygulama & 106 & 52.5 \\
30- Yanlıs yerden ilaç uygulanması \\
(IM veya IV yerin karıştırılması) & 90 & 44.6 \\
31- Yan etkisi olan ilacı & & \\
kullanımına bağlı sorunlar & 129 & 63.7 \\
32- Araç gerecin bozulmasına bağlı \\
hatalar & 132 & 65.2 \\
\hline & & \\
\hline
\end{tabular}

Çalışma kapsamında intörn öğrencilerinin staja çıktıkları hastanede en çok karşılaşılan tıbbi hatalar ve nedenleri incelendiğinde; hastane enfeksiyonlar1 (\%87.6) tedavide gecikme veya yapmama (\%78.2), ameliyat sonras1 komplikasyonlar (\%77.7), İğne/Kesici Alet Yaralanmaları (\%77.2) ve ameliyat komplikasyonları (\%74.3) şeklinde hataların sıralandığı ve bu hatalarin nedenleri arasinda stres $(\% 98.5)$ yorgunluk (\%98), iş yükünün fazla olmas1 (\%96.5), mesleki bilginin yetersiz olması (\%96, tecrübesizlik (94.6), tükenmişlik duygusu (94.1) ve çalışma süresinin uzun olması (\%93.6) olarak belirtilmiştir (Tablo 2, Tablo 3). Sharek ve Classen (2006) ve Alemdar ve Aktaş (2013) yaptıkları çalışmada, hastane enfeksiyonlarının en çok görülen hata türlerinden biri olduğu belirtilmiștir ${ }^{14,15}$

Tablo 3. Tıbbi Hata Nedenlerine İlişkin Bulgular $(\mathrm{N}=202)$

\begin{tabular}{|c|c|c|}
\hline Tibbi Hata Nedenleri & $\mathrm{n}$ & $\%$ \\
\hline 1-Tecrübesizlik & 191 & 94.6 \\
\hline $\begin{array}{l}\text { 2- Mesleki bilginin yetersiz } \\
\text { olması }\end{array}$ & 194 & 96.0 \\
\hline $\begin{array}{l}\text { 3- Çalışma sürelerinin uzun } \\
\text { olması }\end{array}$ & 189 & 93.6 \\
\hline 4- Yorgunluk & 198 & 98.0 \\
\hline 5- Tükenmişlik duygusu & 190 & 94.1 \\
\hline 6- Stres & 199 & 98.5 \\
\hline $\begin{array}{l}\text { 7-Olumsuz fiziksel (1s1, 1şık, } \\
\text { gürültü) ortam }\end{array}$ & 180 & 89.1 \\
\hline $\begin{array}{l}\text { 8- Hataları önleyici sistem } \\
\text { olmaması }\end{array}$ & 174 & 86.1 \\
\hline $\begin{array}{l}\text { 9-Protokol ve prosedürlerin } \\
\text { olmaması ya da anlaşılır } \\
\text { olmaması }\end{array}$ & 171 & 84.7 \\
\hline 10- İletişim eksikliği & 191 & 94.6 \\
\hline $\begin{array}{l}\text { 11-Doktor istemlerinin } \\
\text { anlaşılama-ması (yazının veya } \\
\text { dilin kötü olması) }\end{array}$ & 179 & 88.6 \\
\hline 12- İş yükünün fazla olması & 195 & 96.5 \\
\hline $\begin{array}{l}\text { 13-Görev, yetki ve } \\
\text { sorumlulukların } \\
\text { tam belirlenmemiş olması }\end{array}$ & 185 & 91.6 \\
\hline $\begin{array}{l}\text { 14-Ebelere görev dışı } \\
\text { (sekreterlik) işlerin yüklenmesi }\end{array}$ & 169 & 83.7 \\
\hline $\begin{array}{l}\text { 15- Aylık nöbet sayılarının fazla } \\
\text { olması }\end{array}$ & 178 & 88.1 \\
\hline $\begin{array}{l}\text { 16- Çalışan ebe sayısının az } \\
\text { olması }\end{array}$ & 167 & 82.7 \\
\hline $\begin{array}{l}\text { 17-Hemşirelerin/Ebelerin } \\
\text { çalıştıkları birimin sabit } \\
\text { olmaması }\end{array}$ & 163 & 80.7 \\
\hline $\begin{array}{l}\text { 18-Nöbet değişimlerine dikkat } \\
\text { edilmemesi }\end{array}$ & 155 & 76.7 \\
\hline $\begin{array}{l}\text { 19- Hastanın tedavisi ve bakımı } \\
\text { ile ilgili bilgilerin eksik olması } \\
\text { ya da unutulması }\end{array}$ & 168 & 83.2 \\
\hline $\begin{array}{l}\text { 20-Kayıtların düzenli } \\
\text { tutulmaması }\end{array}$ & 156 & 77.2 \\
\hline $\begin{array}{l}\text { 21-Yöneticilerden memnun } \\
\text { olunmaması }\end{array}$ & 184 & 91.1 \\
\hline 22- Mesleğin sevilmemesi & 188 & 93.1 \\
\hline $\begin{array}{l}\text { 23-Mesleğe yönelik hizmet içi } \\
\text { eğitimlerin olmaması }\end{array}$ & 185 & 91.6 \\
\hline
\end{tabular}

Özata ve Altunkan'ın (2010) çalışmasında da en çok görülen hata türünün hastane enfeksiyonları olduğu (2.26), ve sirasıyla yatak yaraları (1.83) 
ameliyat sonras1 komplikasyonlar (1.70) ameliyat komplikasyonları (1.67), iğne-kesici alet yaralanmaları (1.65) ve tedavide gecikme veya yapmama (1.42) belirtilmiştir. ${ }^{2}$ Literatürde hemşirelerin yaptıkları malpraktis nedenlerine ilişkin bulgular incelendiğinde, Şahin ve

Tablo 4. MEÖ ve Alt Ölçeklerin Puan Ortalamaları

\begin{tabular}{lcc}
\hline \multicolumn{1}{c}{$\begin{array}{c}\text { MEÖ ve Alt } \\
\text { Ölçekler }\end{array}$} & $\begin{array}{l}\text { Dağılım } \\
\text { aralı̆̆ } 1\end{array}$ & $\mathrm{X} \pm$ SS \\
\hline $\begin{array}{l}\text { Illaç ve } \\
\text { Transfüzyon }\end{array}$ & $18-90$ & $78.36 \pm 12.42$ \\
Uygulamaları & & \\
\hline Düşmeler & $12-60$ & $17.98 \pm 4.56$ \\
\hline İetişim & $5-25$ & $19.31 \pm 5.44$ \\
\hline $\begin{array}{l}\text { Hasta } \\
\text { izlemi/Malzeme } \\
\text { Güvenliği }\end{array}$ & $12-45$ & $35.23 \pm 7.04$ \\
\hline $\begin{array}{l}\text { Hastane } \\
\text { Enfeksiyonları }\end{array}$ & $12-60$ & $49.72 \pm 9.11$ \\
\hline Toplam & $54-245$ & $200.62 \pm 33.07$ \\
\hline
\end{tabular}

Özdemir (2015), Alemdar ve Aktaş (2013) ve Kahriman ve Öztürk (2016) yaptıkları çalışmada, hemşirelerin hata yapma nedenlerini iş yükünün çok olması, yorgunluk, çalışan hemşire sayısının yetersiz olması ve çalışılan birimin sürekli değișmesi gibi faktörlerin neden olduğu belirtilmiştir. ${ }^{15-17}$ Așt1 ve Kıvanç'ın (2003) çalışmasında, hemşirelerin \%23.3“ü uzun çalışma saatlerinin olmasını, \%17'si ise hemşire sayısının yetersizliğini ve yorgunluğu hata sebebi olarak gösterdikleri belirtilmiştir ${ }^{18}$ Göktaş'ın (2007) çalışmasında günlük 12 saatten fazla çalışan hemşirelerin daha fazla olumsuz olaylar yaşadığ 1 belirtilmiştir. ${ }^{19}$ Sezgin (2007) hemşirelerin ilaç uygulama hatalarının önemli nedenleri olarak ilk beş sırada; hemşire başına düşen hasta yoğunluğu, dikkat dağılması ve işe yoğunlaşamama, fazla mesai saatleri, uygulanan tedavi ve hastayla ilgili yeterli bilgi sahibi olunmamasını göstermiştir. ${ }^{20}$ Özata ve Altunkan'ın (2010) yaptığı çalışmaya göre, tıbbi hata nedenlerinin başında ise; iş yükünün çok olması, çalışan hemşire sayısının yetersiz olması, hemşirelere görev dişı işlerin yüklenmesi, stres ve yorgunluk gelmektedir. ${ }^{2} \mathrm{Bu}$ sonuçlar doğrultusunda çalışma sonuçlarımız, literatür ile büyük benzerlik göstermektedir.

$\mathrm{Bu}$ çalışmada, intörn öğrencilerin, ölçeğin tüm alt boyutlarına yüksek oranda olumlu puan verdikleri saptanmıştır. Ölçeğinin bu alt boyutları incelendiğinde, ilaç ve transfüzyon uygulamaları alt boyut puan ortalamasının en yüksek olduğu, bu nedenle tıbbi hataya eğilimlerinin bu alt boyutta daha az olduğu, düşmeler alt boyut puan ortalamasının ise en düşük olduğu ve bu nedenle tıbbı hata eğilimin bu alt boyutta daha fazla olduğu saptanmıştır. Cebeci ve ark'nın (2012) ve Avşar ve ark'nın (2016) yaptıkları çalışmada, hemşirelerin ölçeğin tüm alt boyutlarında yüksek puan aldığı, İlaç ve Transfüzyon Uygulamaları" alt boyut puan ortalamasının en yüksek olduğu, düşmeler ve hasta izlemi/malzeme güvenliği alt boyut ortalamalarının ise en düşük puanı olduğu saptanmıştır. ${ }^{21,22}$ Ancak Şahin ve Özdemir'nin (2015), Özkan ve ark.'nın (2011) ve Ersun ve ark.'nın (2013) yaptıkları çalışmalarda ise hemşirelerin ölçeğin tüm alt boyutlarında düşük puan aldığı, İlaç ve Transfüzyon Uygulamaları" alt boyut puan ortalamasının en düşük olduğu bu nedenle tıbbi hataya eğilimlerinin bu alt boyutta daha yüksek olduğu saptanmıştır. ${ }^{16,23,24}$ Çalışma sonuçlarımız literatür ile tam olarak paralellik göstermemektedir. Bu farklılıkların sebebi farklı kurumlarda ve gruplarda yapilmasindan dolay1 olabilir. Ayrıca çalışmanın yapıldığı hastanede kalite çalışmalarının devam etmesi, hasta güvenliği ve tıbbi hatalara yönelik hizmet içi eğitimlerin yapılması bu sonuca katkıda bulunmuş olabilir

\section{Sonuç Öneriler}

Malpraktis Eğilim Ölçeği'nin toplam puan ortalamas1 200. $62 \pm 33.07$ (54-245 puan aras1) olup intörn öğrencilerinin düşük düzeyde tıbbi hata eğilimi olduğu saptanmıştır. Ölçeğin "ilaç ve transfüzyon uygulamaları" alt boyut puan ortalamas1 78.36 \pm 12.42 ,"hastane enfeksiyonlar1" alt boyut puan ortalamas1 49.72 \pm 9.11 , "hasta izlemi ve malzeme güvenliği" alt boyut puan ortalamas1 35.23 \pm 7.04 , "düşmeler" alt boyut puan ortalaması $17.98 \pm 4.56$ "iletişim" alt boyut puan ortalamas1 $19.31 \pm 5.44$ olarak bulunmuştur.

Çalışmamızın sonuçları olumlu bir sonuç olarak değerlendirilmekle birlikte, intörn öğrencilerinin staj süresince hemşireler ve ebeler tarafından dışlanma veya okuldan ceza alma korkusu gibi nedenlerle ölçekte yer alan sorulara yüksek puanlar vermiş olmaları da imkân dâhilindedir.

Hemşirelik ve ebelik intörn öğrencilerine uygulama stajlarında yönetsel denetimlerin yanı sira niteliksel ve niceliksel değerlendirmelerle malpraktisi önleme konusunda eğitim gereksinimleri belirlenmeli ve eğitimlerin sürekliliği ve güncelliği sağlanmalıdır. Hemşire ve ebelere mesleğe başlamadan önce, malpraktisi önleme konusunda bilgitutum- 
davranış alanları belirgin olan ve spesifik hedeflere yönelik, hizmetiçi eğitim programları uygulanmalıdır. Malpraktisi önleme hemşirelik ve ebelik okullarında ayrı bir ders olarak müfredata konuabilir

\section{Kaynaklar}

1. JCAHO. Sentinel Event Statistics, 2006 (Erişim tarihi:01.06.2016) Erişim adresi: www.jointcommission.org/Library/TM_ hysicians/ mp_11_06.htm,

2. Özata M, Altunkan H. Hastanelerde Tibbi Hata Görülme Sıklıkları, Tıbbi Hata Türleri Ve Tibbi Hata Nedenlerinin Belirlenmesi: Konya Örneği [Fruquency of medical errors in hospitals, determination of medical errors types and medical errors:Konya Sample].Tıp Araştırmaları Dergisi [Journal of Medical Research] 2010;8(2):100-11.

3. Aygin D. Cengiz H. İlaç uygulama hataları ve hemşirenin sorumluluğu [Drug administration errors and the responsibility of a nurse].Şişli Etfal Hastanesi Tıp Bülteni [The Medical Bulletin of Şişli Etfal Hospital] 2011; 45(3):110-114.

4. Güngör P, Doğan Merih Y, Yaşar Kocabey M, "Farklı ülkelerin malpraktis konusunda yasal düzenleme girişimleri, zorunlu mali sorumluluk sigortası"[Legal arrangement attempts of different countries about malpractice: compulsory financial liability insurance approaches] Zeynep Kamil Tip Bülteni [Medical Bulletin of Zeynep Kamil] 2012;43(4):128-138

5. Saygın T, Keklik B. "Tıbbi hata nedenleri üzerine bir araştırma: Isparta İli Örneği”[A study about causes of medical errors: 1sparta province sample].Hacettepe Sağllk İdaresi Dergisi [Hacettepe Journal of Health Administration] 2014;17(2):100-117

6. Bilge Y, Geçim E. Medikolegal düzlem tıpta uygulama hataları [Medicolegal platform for malpractice] 1. Bask1, Ankara, Matbaa Promosyon ve Reklam hizmetleri, 2013. p 713.

7. Akalın HE. Yoğun bakım ünitelerinde hasta güvenliği [ Patient safety in intensive care units].Yoğun Bakım Dergisi [Turkısh Journal Of Intensive Care Medicine] 2005; 5 (3):141-146.

8. Menachemi N, Shewchuk RM, O’Connor SJ, Berner ES, Allison JJ. Perceptions of Medical Errors by Internal Medicine Residents: Development and Validation of a
New Scale. Quality Management in Health Care, 2005; 14 (3):144-154.

9. Işık $O$, Akbolat $M$, Çetin $M$, Çimen $M$. Hemşirelerin bakışıyla tıbbi hataların değerlendirilmesi [The causes of medical error from the perspective of nurses], TAF Preventive Medicine Bulletin, 2012;11(4):421-430.

10. Kohn, Linda T, Janet M. Corrigan, and Molla S. Donaldson, eds. To err is human: building a Safer Health System. Vol. 6. National Academies Press, 2000.

11. Tütüncü Ö. Küçükusta D. Hasta güvenliği kültürü ve hemşirelere yönelik bir uygulama [An application on patient safety culture and nurse]. Hastane Yönetimi Dergisi [Journal of Hospital Management] 2006;10(2):61-68.

12. Ertem G, Oksel E, Akbıyık A. Hatalı Tibbi Uygulamalar (Malpraktis) ile İlgili Retrospektif Bir İnceleme [A retrospective review about the malpractice applications in medicine], Dirim Tip Gazetesi [Dirim Medical Newspaper] 2009; 84(1 ): 1-10.

13. Özata M, Altunkan H. Hemşirelikte tıbbi hataya eğilim ölçeğinin geliştirilmesi, geçerlilik ve güvenilirlik analizinin yapılmas1 [Development of malpractice trend scale in nursing and validity and reliability analysis], II. Uluslararası Sağlıkta Performans ve Kalite Kongresi Bildiriler Kitab1. Ankara: 2010b.

14. Sharek PJ, Classen D. The İncidence of adverse events and medical error in pediatrics,Pediatric Clinics Of North America, 2006;53:1067-1077.

15. Alemdar DK, Aktaş YY. Türkiye'de hemșirelik hizmetlerinde tıbbi hata türleri ve nedenleri [Medical error types and causes made by nurses in Turkey] TAF Preventive Medicine Bulletin 2013; 12(3) :307-314.

16. Şahin Akgün Z., Özdemir Karadaş F. Hemşirelerin tıbbi hata yapma eğilimlerinin incelenmesi [Examination of the tendency for nursing malpractice and affecting Factors]. Hemşirelikte Eğitim ve Araştırma Dergisi [Journal of Nursing Education and Research] 2015;12 (3): 210-214.

17. Kahriman, İ, Öztürk H. "Evaluating medical errors made by nurses during their diagnosis, treatment and care practices. Journal of Clinical Nursing, 2016; 25(19-20) : 28842894.

18. Aştı T, Kıvanç M. Ağız yolu ile ilaç verilmesine ilişkin hemşirelerin bilgi ve uygulamalar1 [Nurses information and 
application related to the administration of oral medication], Atatürk Üniversitesi Hemşirelik Yüksekokul Dergisi [Ataturk University School of Nursing Journal] 2003;6(3):1-7

19. Göktaş S. Bir kamu hastanesinde hemşire istihdamının hasta güveliğine etkisi [Impact on employment of nurses for patient safety in a public hospital] [Yüksek Lisans Tezi ].Haliç Üniversitesi, Sağlı Bilimler Enstitüsü [ Institute of Medical Sciences, Haliç University] , İstanbul, Turkey, 2007

20. Sezgin B. Kalite belgesi alan hastanelerde çalışma ortamı ve hemşirelik uygulamalarının hasta ve hemşire güvenliği açısından değerlendirilmesi [Evaluation of work environment and patient and nurse safety of nursing practices in hospitals which have received qyality certificate] [Doktora Tezi], İstanbul Üniversitesi, Sağlık Bilimler Enstitüsü [Institute of Medical Sciences, Haliç University], İstanbul, Turkey,2007.

21. Cebeci F. Gürsoy E. Tekingündüz S. Hemşirelerin tıbbi hata yapma eğilimlerinin belirlenmesi [Determining the level of tendency in malpractice among nurses], Anadolu Hemşirelik ve Sağlık Bilimleri Dergisi [Journal of Anatolia Nursing and Health Sciences ] 2012; 15(3):188-196

22. Avşar G, Atabek Armutçu A, Karaman Özlü Z. Determining the level of tendency in malpractice of nurses: A hospital sample. HSP 2016 3(2):115-122.

23. Özkan S, Kocaman G, Öztürk C, Seren S. Frequency of pediatric medication administration errors and contributing factors. Journal of Nursing Care Quality, 2011; 26(2):136-143.

24. Ersun A, Başbakkal Z, Yardımcı F, Muslu G, Beytut D. Çocuk hemşirelerinin tıbbi hata yapma eğilimlerinin incelenmesi [A study of the malpractice trends in pediatric nurses] Ege Üniversitesi Hemşirelik Fakültesi Dergisi [Journal of Ege University Nursing Faculty] 2013; 29(2):33-45. 